\title{
Family structure, neonatal infection, and hay fever in adolescence
}

\author{
David P Strachan, Elizabeth M Taylor, Robert G Carpenter
}

\begin{abstract}
Objective-To determine whether increased numbers of siblings and infection in early life protect against allergic sensitisation.
\end{abstract}

Design-Historical cohort study.

Setting-Sheffield, UK.

Subjects-11 765 children aged 11-16 years for whom a history of neonatal infectious illness had been recorded systematically at 1 month of age.

Methods-A history of hay fever and family structure was obtained by postal questionnaire; neonatal illness history was ascertained from health visitor records; 723 children underwent skin prick testing with mixed grass pollen extract.

Results-The prevalence of hay fever was reduced $(p<0.0001)$ among children of younger mothers, and those from larger families. The number of older siblings exerted a stronger independent effect than the number of younger siblings $(p<0.001)$. Infants breast fed exclusively during the first month were at higher risk $(p<0.05)$ of subsequent hay fever, independent of demographic factors. Adolescents at high risk of hay fever by virtue of their family structure were more likely to be sensitised to grass pollen $(\mathbf{p}<0.002)$. No significant relations emerged between hay fever and infection in the first month of life, even among children born in June.

Conclusions-The association of hay fever with family structure is not due to reporting bias and reflects an environmental influence on allergic sensitisation. The effects of sibship size, birth order, and infant feeding are consistent with a protective influence of postnatal infection. The first month of life and the first postnatal exposure to allergen are not the critical periods during which this protective effect is determined.

(Arch Dis Child 1996; 74: 422-426)

Keywords: hay fever, allergy, neonatal infection, infant feeding.

Western Bank,

Sheffield S10 2TH

E M Taylor

Department of

Epidemiology and

Population Sciences,

London School of

Hygiene and Tropical

Medicine, Keppel

Street, London

WC1E 7HT

R G Carpenter

Correspondence to: Dr Strachan.

Accepted 29 January 1996 siblings ${ }^{1-3}$ led to speculation that infection acquired by household contact in early childhood might protect against allergic sensitisation. ${ }^{15}$

Children from large families are at reduced of developing hay fever, ${ }^{12}$ eczema, ${ }^{12}$ and allergic sensitisation to common aeroallergens. ${ }^{34}$ The observation that older siblings appear to
Recent advances in our understanding of $T$ lymphocyte differentiation ${ }^{6}$ have suggested a possible mechanism for such a protective effect. Production of immunoglobulin $\mathrm{E}$ responses and symptomatic atopic disease are associated with the presence of allergen specific $\mathrm{T}$ helper 2 (Th2) cells, whereas in non-atopic individuals non-pathogenic responses to the same antigens are mediated by $\mathrm{T}$ helper 1 (Th1) cells. Th1 and Th2 cells develop in early life from uncommitted precursors and the direction of differentiation can be influenced by the levels of cytokines prevailing at the time of challenge with antigen. The 'natural' immune response to bacterial and viral infections increases the production of interferon $\gamma$ and interleukin-2, cytokines which selectively enhance the development of Th1-type lymphocytes, and suppress Th2-type differentiation. ${ }^{7}$

These observations have led to a more specific hypothesis, that infections occurring in the first few months of life, perhaps specifically at the time of first exposure to the relevant allergen, may inhibit the proliferation of Th2 cell clones and thereby prevent allergy. ${ }^{8}$ An alternative hypothesis is that a stable state of Th1-type or Th2-type predominance is not reached for some five to seven years after birth, and may be influenced by the cytokine environment prevailing at each of multiple exposures to a specific allergen. ${ }^{6}$

An opportunity to investigate the effect of family structure on risk of allergic disease and to test specifically the effect of infectious illness in early infancy arose in Sheffield, UK, where almost all babies born since 1975 have been visited by a health visitor at 1 month of age to identify those at risk of sudden infant death. ${ }^{9}$ We describe here a longitudinal study created by linking these health visitor records to data from a survey of allergic disease among teenagers throughout Sheffield.

\section{Methods}

HEALTH VISITOR SCREENING PROGRAMME

Each baby born in Sheffield since August 1975 has been included in a screening programme to predict the risk of sudden infant death and other perinatal outcomes (the Sheffield child development study). ${ }^{910}$ Abstracts of the obstetric records, including maternal age and parity, were supplemented by a detailed interview with the parent of each child in the home at 1 month of age. The interviews were conducted by health visitors using a questionnaire which remained largely unchanged from 1975 to 1988. This enquired about illnesses in the baby since birth, including the following symptoms suggestive of infection: runny nose, 
cough, diarrhoea, skin infection, sticky eye, and thrush. The questionnaire also included a history of respiratory, gastrointestinal, skin, or other infections in family members since the child was born. From August 1976 onwards the date of birth of the next older child in the family was included. Linked birth abstracts and health visitor interviews were available for more than $95 \%$ of the births in Sheffield throughout the period August 1975 to July 1980.

\section{ALLERGY SURVEY}

In November 1991, questionnaires were distributed to the parents of 23054 children in the first to fifth years attending secondary schools throughout Sheffield. One of the 35 schools declined to participate. Replies were obtained for 18203 children (79\% response). The questionnaire enquired about both symptoms and diagnoses of asthma, hay fever, and eczema, about birth details (which were used for record linkage), and the position of the child in the family. Results are presented here for hay fever, defined as positive response to the question 'Has a doctor ever told you that your child has hay fever?'. Broadly similar results were obtained using a symptom based definition (seasonal sneezing, running or blocking of the nose, not associated with a cold or the 'flu, occurring in the past 12 months).

\section{DATA LINKAGE}

Among the 18203 questionnaire respondents, there were 15222 singletons born in Sheffield. Using a combination of computer matching by date and place of birth, maternal age and parity
(11 423 children), and clerical searches by surname (2272 children), 13695 (90\%) were unambiguously traced in the Sheffield child development study birth registers. The computer matching was checked by clerical searches for 702 children, and only $7(1 \%)$ were found to be incorrect. The analysis presented here is restricted to 11765 children with a 1 month health visitor interview completed at age 24-37 days, of whom 7783 (66\%) were visited 28-33 days after birth.

\section{SKIN PRICK TESTING}

Children attending 14 schools underwent skin prick testing with extracts of mixed grass pollen, positive (1:999 histamine) and negative (saline) controls (Allergopharma, Germany). Tests were carried out by a single observer using $1 \mathrm{~mm}$ flanged lancets inserted vertically through the drops of test solution placed on the volar aspect of the forearm. The maximum and perpendicular weal diameters were recorded after 10 minutes and the mean diameter used in the analysis.

Among the children with fully linked data, 1386 were selected for the skin prick survey. Two groups, at 'high' and 'low' risk of doctor diagnosed hay fever were defined from a multiple logistic regression of the questionnaire data, including, as explanatory variables, position in the family and maternal age. Children from the 14 participating schools whose family structure placed them in the top $10 \%$ and bottom $25 \%$ of the risk distribution were contacted. The parents of 778 children $(56 \%)$ gave consent and after two visits to each participating school, 723 children were tested $(52 \%)$.

\section{STATISTICAL ANALYSIS}

Data linkage and cross tabulations were carried out using the Statistical Analysis System (SAS). ${ }^{11}$ Multiple logistic regression analyses used the generalised linear interactive modelling package (GLIM). ${ }^{12}$ These analyses adjusted for sex and year of birth in addition to the factors listed in the tables.

\section{Results}

Among 17968 children with valid parental responses, $2954(16.4 \%)$ had a history of doctor diagnosed hay fever. Among the subjects included in the analysis, the prevalence was also $16.4 \%(1932 / 11765)-18.0 \%(1039 / 5780)$ for boys and $14.9 \%(893 / 5985)$ for girls.

\section{HAY FEVER AND FAMIIY STRUCTURE}

Table 1 shows the relation between hay fever prevalence and family structure. Before adjustment for other factors, the prevalence declined with increasing number of older and younger siblings, and increased with wider birth spacing and increasing maternal age. The prevalence of seasonal non-infective rhinitis in the past year followed a very similar pattern, varying from $11 \cdot 8 \%$ to $16 \cdot 7 \%$ with increasing adjusted for other factors in the table, sex, and year of birth by logistic regression.
bFirstborns excluded. Interval was not recorded for births during August 1975 to July 1976 . cSingle parent or parent still at school. dExcluded from the test for linear trend. 
Table 2 Prevalence of doctor diagnosed hay fever by personal and family history of infectious illness during the first month of life, for all births, and for birth during Fune only

\begin{tabular}{|c|c|c|c|c|}
\hline & \multicolumn{2}{|l|}{ All months of birth } & \multicolumn{2}{|l|}{ Fune births } \\
\hline & $\begin{array}{l}\text { Illness present } \\
\%(n / N)\end{array}$ & $\begin{array}{l}\text { Illness absent } \\
\%(n / N)\end{array}$ & $\begin{array}{l}\text { Illness present } \\
\%(n / N)\end{array}$ & $\begin{array}{l}\text { Illness absent } \\
\%(n / N)\end{array}$ \\
\hline $\begin{array}{l}\text { Symptoms in the child } \\
\text { Runny nose } \\
\text { Cough } \\
\text { Diarrhoea } \\
\text { Skin infection } \\
\text { Eye infection } \\
\text { Thrush } \\
\text { Any of above }\end{array}$ & $\begin{array}{l}15 \cdot 9(623 / 3912) \\
17 \cdot 4(169 / 972) \\
16 \cdot 8(79 / 471) \\
17 \cdot 1(127 / 744) \\
16 \cdot 9(504 / 2984) \\
13 \cdot 7(125 / 914) \\
16 \cdot 4(1132 / 6906)\end{array}$ & $\begin{array}{l}16 \cdot 7(1309 / 7853) \\
16 \cdot 4(1763 / 10793) \\
16 \cdot 4(1853 / 11294) \\
16 \cdot 4(1805 / 11021) \\
16 \cdot 3(1428 / 8781) \\
16 \cdot 7(1807 / 10851) \\
16 \cdot 5(800 / 4859)\end{array}$ & $\begin{array}{l}15 \cdot 5(42 / 271) \\
15 \cdot 4(8 / 52) \\
11 \cdot 6(5 / 43) \\
22 \cdot 6(12 / 53) \\
15 \cdot 7(41 / 261) \\
11 \cdot 8(10 / 75) \\
15 \cdot 7(86 / 548)\end{array}$ & $\begin{array}{l}15 \cdot 5(107 / 689) \\
15 \cdot 5(141 / 767) \\
15 \cdot 7(144 / 773) \\
15 \cdot 1(137 / 907) \\
15 \cdot 5(108 / 699) \\
15.9(139 / 875) \\
15.3(63 / 412)\end{array}$ \\
\hline $\begin{array}{l}\text { Infection in the family } \\
\text { Respiratory } \\
\text { Gastrointestinal } \\
\text { Skin } \\
\text { Other } \\
\text { Any of above }\end{array}$ & $\begin{array}{l}16 \cdot 2(818 / 5055) \\
17 \cdot 0(161 / 946) \\
15 \cdot 4(82 / 533) \\
15 \cdot 5(35 / 226) \\
16 \cdot 2(962 / 5935)\end{array}$ & $\begin{array}{l}16 \cdot 6(1114 / 6710) \\
16 \cdot 4(1771 / 10819) \\
16 \cdot 5(1850 / 11232) \\
16 \cdot 4(1897 / 9642) \\
16 \cdot 6(970 / 5830)\end{array}$ & $\begin{array}{l}16 \cdot 0(51 / 319) \\
16 \cdot 7(13 / 78) \\
14 \cdot 8(9 / 61) \\
23 \cdot 8(5 / 16) \\
15 \cdot 7(64 / 407)\end{array}$ & $\begin{array}{l}15 \cdot 3(98 / 641) \\
15 \cdot 4(136 / 882) \\
15 \cdot 6(140 / 899) \\
15 \cdot 3(144 / 939) \\
15 \cdot 4(85 / 553)\end{array}$ \\
\hline
\end{tabular}

maternal age, from $17 \cdot 0 \%$ for firstborn children to $11.3 \%$ for children with three or more older siblings, and from $15.4 \%$ to $9.6 \%$ with increasing numbers of younger siblings.

The factors listed in table 1 were intercorrelated and multiple logistic regression was required to determine their independent effects on hay fever prevalence. Mutually adjusted odds ratios derived from the logistic regression model are also shown in table 1. After adjustment for other factors, the effect of maternal youth was strengthened and was statistically highly significant. Both the number of older siblings and the number of younger siblings were inversely related to hay fever prevalence at a high degree of significance. The effect of older siblings was significantly $(p<0.001)$ more influential than the number of younger siblings, although both exerted an independent effect on hay fever prevalence. There was a trend towards a lower prevalence with closer birth spacing, but this was of only borderline significance $(0 \cdot 05<\mathrm{p}<0 \cdot 1)$ after adjustment for other factors. There was no independent effect of father's age after adjustment for mother's age.

Table 1 also shows the association of hay fever with infant feeding and parental education. After adjustment for other factors, there was virtually no effect of parental education, but a significantly high prevalence of hay fever was observed among adolescents who had been exclusively breast fed during the first month of life, compared to bottle fed infants and those transferred from breast to bottle.

\section{FAMILY STRUCTURE AND EARLY INFECTION} The proportion of children exposed to infection in the family in the first month of life varied with birth order: $38 \%$ (1971/5166) for firstborn children, compared to 59\% (2650/4524), 66\% (904/1379), and 59\% (410/696) for children with one, two, and three or more older siblings, respectively. The corresponding proportions with a documented personal history of infection in the neonatal period were less variable: $55 \%(2846 / 5166), 62 \% \quad(2782 / 4524), 62 \%$ (855/1379), and 61\% (423/696), respectively, for children with no, one, two, and three or more older siblings.

A family history of infection in the first month of life was slightly less common among the offspring of younger mothers: $47 \%$ (521/1116), $48 \%(1728 / 3584), 50 \%(2143 / 4257)$, and $55 \%$ (1543/2808) for mothers aged <20, 20-24, $25-29$, and $30+$ years at the time their child was born. The corresponding proportions reporting one or more infectious illnesses in their infant by one month of age were $63 \%$ (703/1116), $61 \%(2175 / 3584), 57 \%(2423 / 4257)$, and $57 \%$ (1605/2808), respectively. Thus a personal history of neonatal infection was slightly more common in the offspring of younger mothers.

\section{HAY FEVER AND EARLY INFECTION}

Table 2 shows the prevalence of hay fever in children with a documented personal or family history or infection in the first month of life. Overall, there was little effect of early infection on hay fever prevalence, and the only specific infection associated with a significant reduction in risk was thrush $(13.7 \% v 16.7 \%$, $\mathrm{p}=0.02$ ). However, after adjustment for age, sex and the family structure variables in table 1 , this association was no longer significant at the $5 \%$ level (adjusted odds ratio $0.85,95 \%$ confidence interval 0.44 to 1.02 ).

The relation between hay fever and neonatal illness or family history of infection in the first month did not differ substantially in subgroups defined by the number of older siblings. There were no statistically significant interactions between these factors $(p>0 \cdot 1)$.

The analysis was further restricted to 960 children born in June, who therefore experienced their first exposure to grass pollen in the neonatal period. Two thirds of these children were placed outdoors for more than two hours each day during the first month of life. The prevalence of hay fever was almost the same among June births with a history of infection in the first month of life as among those without (table 2).

SKIN PRICK RESPONSES

Among the 723 children who participated in the skin prick tests, 235 had been selected as a group at high risk of hay fever, and 488 formed the low risk group. Table 3 shows that the difference between these groups in reported hay fever prevalence $(28 \% v 15 \%, \mathrm{p}<0.0001)$ was closely matched by differences in the prevalence of skin prick positivity to grass pollen, 
Table 3 Prevalence of hay fever and cutaneous reactions to grass pollen by family structure and infant feeding in the subgroup undergoing skin prick testing

\begin{tabular}{|c|c|c|c|c|}
\hline & \multirow[b]{2}{*}{$\begin{array}{l}\text { Number } \\
\text { tested }\end{array}$} & \multirow{2}{*}{$\begin{array}{l}\text { Diagnosed } \\
\text { hay fever } \\
(\%(n))\end{array}$} & \multicolumn{2}{|c|}{ Skin prick to grass mix } \\
\hline & & & $\begin{array}{l}\text { Weal } \geqslant 3 \mathrm{~mm} \\
(\%(n))\end{array}$ & $\begin{array}{l}\text { Weal } \geqslant 1 \mathrm{~mm} \\
(\%(n))\end{array}$ \\
\hline $\begin{array}{l}\text { Risk score }^{\mathrm{a}} \\
\text { High } \\
\text { Low }\end{array}$ & $\begin{array}{l}235 \\
488\end{array}$ & $\begin{array}{l}28(66) \\
15(73)\end{array}$ & $\begin{array}{l}24(57) \\
14(70)\end{array}$ & $\begin{array}{l}34(81) \\
23(114)\end{array}$ \\
\hline $\begin{array}{l}\text { Mother's age at bir } \\
<25 \\
25-29 \\
30+\end{array}$ & $\begin{array}{l}\text { s) } \\
226 \\
277 \\
220\end{array}$ & $\begin{array}{l}15(33) \\
20(55) \\
23(51)\end{array}$ & $\begin{array}{l}15(33) \\
18(49) \\
20(45)\end{array}$ & $\begin{array}{l}23(53) \\
27(76) \\
30(66)\end{array}$ \\
\hline $\begin{array}{l}\text { Number of siblings } \\
0 \\
1 \\
2 \\
3+\end{array}$ & $\begin{array}{r}75 \\
252 \\
222 \\
174\end{array}$ & $\begin{array}{l}28(21) \\
23(58) \\
18(40) \\
11(20)\end{array}$ & $\begin{array}{l}20(15) \\
22(55) \\
18(38) \\
11(19)\end{array}$ & $\begin{array}{l}28(21) \\
32(80) \\
27(60) \\
20(34)\end{array}$ \\
\hline $\begin{array}{l}\text { Birth interval } \\
<3 \text { Years } \\
3+\text { Years } \\
\text { No older sibling }\end{array}$ & $\begin{array}{l}221 \\
238 \\
264\end{array}$ & $\begin{array}{l}16(35) \\
17(39) \\
25(65)\end{array}$ & $\begin{array}{l}14(30) \\
17(39) \\
22(58)\end{array}$ & $\begin{array}{l}23(50) \\
25(59) \\
33(86)\end{array}$ \\
\hline $\begin{array}{l}\text { Feeding in first mo } \\
\text { Breast } \\
\text { Both } \\
\text { Bottle }\end{array}$ & $\begin{array}{r}267 \\
91 \\
365\end{array}$ & $\begin{array}{l}20(53) \\
16(15) \\
19(71)\end{array}$ & $\begin{array}{l}18(49) \\
18(16) \\
17(62)\end{array}$ & $\begin{array}{l}27(72) \\
32(29) \\
26(94)\end{array}$ \\
\hline
\end{tabular}

${ }^{\text {a}}$ Derived by discriminant analysis of questionnaire data (see Methods).

whether defined as any detectable weal $(34 \% v$ $23 \%, p=0.002$ ), or a weal greater than $3 \mathrm{~mm}$ mean diameter $(24 \% v 14 \%, \mathrm{p}=0.0015)$. Very similar results were obtained using the histamine weal diameter, rather than $3 \mathrm{~mm}$, as the cutoff (data not shown).

The variation in reported hay fever prevalence with sibship size and maternal age in this subgroup was matched very closely by corresponding variations in skin prick responses to pollen extract (table 3 ). These variations were most evident for the larger weal sizes, implying that groups with a high prevalence of hay fever had a greater mean weal diameter on prick testing with grass pollen. There was little difference in the prevalence of positive skin prick reactions among breast fed and bottle fed children (table 3 ).

\section{Discussion}

This large, population based historical cohort study confirms previous observations of an inverse relation between hay fever prevalence and sibship size, ${ }^{12}$ and offers corroborative evidence that position within the sibship and maternal age are also influential. ${ }^{5}$ A new finding is the variation in hay fever prevalence with birth spacing, independent of other factors. Taken individually, these effects are subtle but can be detected at a high level of statistical significance in datasets of this size. However, in combination these aspects of family structure may have a marked effect of hay fever prevalence, greater than variations relating to socioeconomic status or infant feeding. ${ }^{5}$

Our data do not support the recent suggestion that exclusive breast feeding during the first month of life offers substantial protection against respiratory allergy in adolescence. ${ }^{13}$ Indeed, the findings would be more consistent with a small increase in risk of allergy among breast fed infants, as noted in the British 1958 and 1970 birth cohorts. ${ }^{25}$ It is unlikely that selective use of breast feeding by atopic mothers could have influenced these associations greatly, as most of the children were born before a protective effect of prolonged breast feeding was widely publicised in the late 1970 s. $^{14}$

Relations between family structure and reported hay fever were mirrored very closely by the corresponding variations in skin prick reactions to mixed grass pollen. Two other studies have reported inverse correlations between the prevalence of positive skin prick tests and sibship size ${ }^{4}$ or position in the household. ${ }^{3}$ Together, these observations argue strongly that the association of hay fever prevalence with family structure cannot be attributed to differential recognition, reporting, or diagnosis of symptoms, and probably reflects the distribution of the atopic phenotype. ${ }^{5}$

Environmental influences on allergic sensitisation may operate before or after birth. The dominant effect of older siblings would be consistent with either a prenatal or a postnatal influence, but the independent effect of younger siblings suggests that postnatal child contact plays a protective role. The apparent protective effect of maternal youth, which also emerged in an earlier cohort, ${ }^{5}$ would be consistent with influences related to intrauterine development, although it may also reflect different patterns of child care by younger mothers. More detailed studies of allergic disease in relation to obstetric indices and patterns of interpersonal contact in young families are required to clarify the respective roles of the prenatal and postnatal environment in 'programming' allergic sensitisation. ${ }^{15}$

The Sheffield child development study offered a rare, possibly unique, opportunity to test the effect of one specific programming influence: neonatal infection. ${ }^{8}$ This was a large, population based sample in which both neonatal illness and adolescent allergy were ascertained in a systematic manner. No evidence emerged to support the hypothesis that exposure to common infectious illnesses within the first month of life protects against subsequent allergic sensitisation through the preferential selection of Th1 clones, even among children exposed at this time to their first dose of inhaled allergen.

Our findings contrast with a retrospective study of 212 Finnish 7 year olds which found a significant two- to threefold excess of physician diagnosed atopic disease or positive skin prick tests among children with a history of fever, gastrointestinal illness, or otitis media in infancy. ${ }^{16}$ An important limitation of that study was the distant recall by parents of illnesses in the first year of life, whereas in ours, illnesses were recorded within a few days of the neonatal period. However, the information available in Sheffield was limited to parental recall of symptomatic illness in the baby and the family in the first month of life, when maternal antibodies acquired in utero persist in the neonatal circulation and may modulate the immunological response to infection.

Although programming effects from asymptomatic early infection cannot be excluded, our findings strongly suggest that the critical 
period during which sibling contact may influence allergic sensitisation extends well beyond the first month of life. Indeed, the neonatal period may be a protected window during which programming of this type does not occur. This would be consistent with the notion that a stable pattern of allergen specific IgE response may evolve over a number of years, ${ }^{17}$ in relation to repeated exposures to allergen. The process may take longer if allergen exposure is intermittent, as in the case of seasonal aeroallergens, offering multiple windows of opportunity for infection acquired from siblings and playmates to influence the cytokine environment of developing pollen specific $T$ cell clones.

Further epidemiological studies embracing a longer period of child development are required to clarify the relations between postnatal child contact, infectious illness, and programming influences on allergic sensitisation, and to determine the scope for prophylactic intervention during critical periods in immunological development.

We wish to thank all the parents, children, and school teachers who assisted with the 1991 allergy survey; Jayne Thompson and who assisted with the 1991 allergy survey; Jayne Thompson and Janice Pinder for assistance with fieldwork; and all the health
visitors who completed 1 month interviews during 1975-1980 visitors who completed 1 month interviews during 1975-1980 and who contributed in many other ways to the Sheffield Child funded by the National Asthma Campaign.

Strachan DP. Hay fever, hygiene, and household size. $B M \mathcal{F}$ 1989; 299: 1259-60,

2 Golding J, Peters T. Eczema and hay fever. In: Butler N,
Golding J, eds. From birth to five. A study of the health and behaviour of Britain's five-year-olds. Oxford: Pergamon Press, 1986: 171-86.

3 Strachan DP, Griffiths JM, Anderson HR, Johnston IDA. Allergic sensitisation and position in the sibship: a national study of young British adults [abstr]. Thorax 1994; 49: 1053P.

4 von Mutius E, Martinez FD, Fritzsch C, Nicolai T, Reitmar $P$, Thiemann $\mathrm{HH}$. Skin test reactivity and number of P, Thiemann HH. Skin test re

5 Strachan DP. Epidemiology of hay fever: towards a community diagnosis. Clin Exp Allergy 1995; 25: 296-303.

6 Holt PG. A potential vaccine strategy for asthma and allied atopic diseases during early childhood. Lancet 1994; 344: 456-8.

7 Romagnani S. Human TH1 and TH2 subsets: regulation of differentiation and role in protection and immunopathology. Int Arch Allergy Immunol 1992; 98: 279-85.

8 Martinez FD. Role of viral infections in the inception of asthma and allergies during childhood: could they be protective? Thorax 1994; 49: 1189-91.

9 Carpenter RG, Gardner A, McWeeny PM, Emery JL. Multistage scoring system for identifying infants at risk of Multistage scoring system for identifying infants at risk
unexpected death. Arch Dis Child 1977; 52: 606-12.

10 unexpected death. Arch Dis Child 1977; 52: 606-12. arpenter RG, Gardner A, Jepson M, Taylor EM, Salvin A,
Sunderland R, et al, and the health visitors of Sheffield. Sunderland $R$, et al, and the health visitors of Sheffield.
Prevention of unexpected infant death. Evaluation of the first seven years of the Sheffield intervention programme. Lancet 1983; i: 723-7.

11 SAS System Inc. SAS/STAT user's guide, version 6, 4th edition. Cary, North Carolina: SAS System Inc, 1990.

12 Francis B, Green M, Payne C, eds. The GLIM system release 4 manual. Oxford: Clarendon Press, 1993.

13 Saarinen UM, Kajosaari M. Breastfeeding as prophylaxis against atopic disease: prospective follow-up study until 17 years old. Lancet 1995; 346: 1065-9.

14 Saarinen UM, Kajosaari M, Blackman A, Siimes MA. Saarinen UM, Kajosaari M, Blackman A, Siimes MA.
Prolonged breastfeeding as prophylaxis for atopic disease. Prolonged breastfeeding as prophylaxis for atopic disease. 5 Lancet 1979; ii: 163-8.

5 Strachan DP. Is allergic disease programmed in early life? Clin Exp Allergy 1994; 24: 603-5.

16 Backman A, Björkstén F, Ilmonen S, Juntunen K, Suoniemi I. Do infections in infancy affect sensitization to airborne allergens and development of allergic disease? Allergy 1984; 39: 309-15.

17 Hattevig G, Kjellman B, Björkstén B. Appearance of IgE antibodies to ingested and inhaled allergens during the first 12 years of life in atopic and non-atopic children. Pediatr Allergy Immunol 1993; 4: 182-6. 